\title{
Effect of the combined action of Quercus cortex extract and probiotic substances on the immunity and productivity of broiler chickens
}

\author{
G. K. Duskaev ${ }^{1}$, S. G. Rakhmatullin ${ }^{1}$, N. M. Kazachkova ${ }^{1}$, Y. V. Sheida², I. N. Mikolaychik ${ }^{3}$, L. A. Morozova ${ }^{3}$ and
} B. H. Galiev ${ }^{1}$

1. Department for Feeding Agricultural Animals and Fodder Technology, Federal Research Centre of Biological Systems and Agro-technologies of the Russian Academy of Sciences, Orenburg - 460 000, Russia; 2. Institute of Bioelements, Orenburg State University, Orenburg, 460018, Russia; 3. Kurgan State Agriculture Academy, Lesnikovo, Ketovsky, Kurgan Region, 641300, Russia.

Corresponding author: G. K. Duskaev, e-mail: gduskaev@mail.ru

Co-authors: SGR: shahm2005@rambler.ru, NMK: yagoda-oren@mail.ru, YVS: elena- shejjda@mail.ru, INM: min_ksaa@mail.ru, LAM: morozova-la72@mail.ru, BHG: bgaliev@yandex.ru Received: 21-06-2018, Accepted: 07-09-2018, Published online: 13-10-2018

doi: 10.14202/vetworld.2018.1416-1422 How to cite this article: Duskaev GK, Rakhmatullin SG, Kazachkova NM, Sheida YV, Mikolaychik IN, Morozova LA, Galiev BH (2018) Effect of the combined action of Quercus cortex extract and probiotic substances on the immunity and productivity of broiler chickens, Veterinary World, 11(10): 1416-1422.

\begin{abstract}
Aim: This study was designed to investigate the synergistic effect of the combined action of probiotic bacterial strains (Bifidobacterium adolescentis and Lactobacillus acidophilus) and Quercus cortex extract as biologically active substances in the feed on the immunity and productivity of Gallus gallus domesticus.

Materials and Methods: For the experiment, 120 7-day-old broiler chickens were selected ( 4 groups, n=30, 3 replicates with 10 birds in each group). The groups were as follows: The reference group - basic diet (BD); experimental Group I - BD $+Q$. cortex extract (Q. cortex), $2.5 \mathrm{ml} / \mathrm{kg}$ of body weight; experimental Group II - BD + probiotic preparation based on $B$. adolescentis, 80.0 million colony-forming units (CFU), and L. acidophilus, 1.0 million CFU (dosage in accordance with the recommendations of the manufacturer); and experimental Group III - BD + probiotic + extract of Q. cortex. The following methods of study were used: Chemiluminescence and biochemical and hematological analysis.

Results: The results of the experiment showed a slight decrease in the level of leukocytes in Groups II ( $p \leq 0.05)$ and III, and of hemoglobin in Group III ( $\mathrm{p} \leq 0.05)$, compared to the reference group. The level of alanine aminotransferase and aspartate aminotransferase in Group II was higher than both the reference group $(p \leq 0.05)$ and the other groups. Introduction of $Q$. cortex extract into the diet increased the level of triglycerides $(\mathrm{p} \leq 0.05)$ and urea in the blood serum. The combined use of probiotic preparations and the extract resulted in an increase in the level of iron in the blood serum by $78.1 \%(\mathrm{p} \leq 0.05)$ in Group III. An increase in indicators of the antioxidant system (catalase increased in Group I by $27.2 \%(p \leq 0.05)$ and by $3.0-12.7 \%$ in other groups; superoxide dismutase increased by $3.0-13.2 \%$ ) and nonspecific immunity ( $\beta$-lysine increased by $8.8-16.0 \%$ ) was noted. Introduction of the extract and probiotic preparation into the diet contributed to increasing the live weight of chickens at the age of 15 days by 5.9 and $7.4 \%$, respectively $(p \leq 0.05)$. In experimental Group II, this trend continued, and by the end of the period, the weight of animals exceeded that of their peers in other groups by $0.7-7.0 \%$. Given the high preservation rate of poultry in the II and III Groups, and the low feed consumption per $1 \mathrm{~kg}$ of live weight gain (by 3.1-6.7\%), the efficiency of growth was higher than in the reference group.
\end{abstract}

Conclusion: Thus, the combined use of probiotic strains of bacteria and Q. cortex extract helped to increase the antioxidant activity of the organism and antimicrobial components of blood plasma compared with broiler chickens with similar growth rates but without the supplementation of this combination.

Keywords: broiler chickens, growth, plant extract, probiotic.

\section{Introduction}

The current trend in animal nutrition is feeding with more "natural" substances as the use of some additives, such as antibiotic drugs in animal feed, is not allowed by law in many countries due to the development of antibiotic-resistant bacteria [1]. This created an increased interest in the poultry industry

Copyright: Duskaev, et al. Open Access. This article is distributed under the terms of the Creative Commons Attribution 4.0 International License (http://creativecommons.org/licenses/ by/4.0/), which permits unrestricted use, distribution, and reproduction in any medium, provided you give appropriate credit to the original author(s) and the source, provide a link to the Creative Commons license, and indicate if changes were made. The Creative Commons Public Domain Dedication waiver (http:// creativecommons.org/publicdomain/zero/1.0/) applies to the data made available in this article, unless otherwise stated. aimed at finding other alternatives that may be safe and accepted by the consumers. Lately, probiotics, prebiotics, herbs, spices, or botanical substances (e.g., essential oils) have been considered as good substitutes [2]. Herbs and trees contain various antioxidants with high potential for protecting nutrients from oxidation in the digestive tract in the process of metabolism and can help develop immunity and contribute to the growth of animals [3]. Some medical effects of medicinal plants are related to their secondary metabolites, such as phenols, essential oils, and saponins [4]. Many herbs have a long history of use, even prehistoric use, in preventing or treating diseases of humans and animals due to their availability, ease of use, and the absence of side effects. However, the results of studying the use of 
herbal mixtures in the diets of broiler chickens have thus far yielded inconsistent results. Some authors claimed a positive effect on broilers' performance [5], while others noted no effect on weight gain, feed consumption, or feed conversion [6]. One of the studied plants is Quercus; this genus has been found to have antioxidant, antifungal, antibacterial, and antitumor activities [7]. The composition of polar fractions of leaves, bark, wood, and galls shows antibacterial and anti-inflammatory activity [8-10], which explains their ethnopharmacological use. Ethanol extract of Q. leucotrichophora showed strong antimicrobial activity against Staphylococcus aureus, Pseudomonas auroginosa, Bacillus subtilis, and Escherichia coli [11]. Physiochemical composition analyses have shown that plants belonging to genus Quercus are rich in lignins, hydrolyzable tannins, ellagitannins, flavane ellagitannins, catechins, flavones and proanthocyanidin glycosides, flavonoids, and simple phenols and proanthocyanidin glycosides $[12,13]$. Probiotics, due to their multipurpose actions, improve animal health and increase the efficiency of poultry production. The interest in using probiotics for poultry has been increasing since animal growth promoters were prohibited in the EU and the associated increased occurrence rate of intestinal infections in poultry mostly caused by Clostridium perfringens. From the literature, it is known that probiotics have a positive effect on the immunity of broilers, including when they are combined with substances or parts of plants $[14,15]$. Immunity indices were maintained at the same level after using strains of Bacillus [16]; Lactobacillus reuteri increases the growth rates of birds at an early age, stimulates the immune response, and reduces the amount of E. coli [17]. Other probiotics do not adversely affect the immunity of birds [18].

Using the selected strains of Lactobacillus as feed additives for poultry may result in similar effects with the effect of growth promoters of antibiotics, resulting in weight gain and better feeding efficiency, and resistance to pathogenic bacteria, such as Salmonella sp. [19], C. perfringens [20,21], E. coli [22], or Campylobacter sp. [23]. Furthermore, adding strains of Lactobacillus into the diet of broilers reduces general fat accumulation [24] and increases size, carcass quality, and egg production [25].

It is assumed that the useful substances of the plant described above, combined with the probiotic, could be used as a feed additive in the broiler diet and to improve growth and carcass quality, stimulate the immune system, and reduce the perceived risk to health. This study aimed to assess the synergistic effect of the combined use of Quercus cortex extract and probiotic substances on immunity and productivity in broiler chickens.

\section{Materials and Methods}

\section{Ethical approval}

Poultry maintenance and procedures during the experiments met the requirements of the instructions and recommendations of Russian regulations (order of the Ministry of Health of the USSR No. 755 of 12.08.1977) and "The Guide for Care and Use of Laboratory Animals (National Academy Press, Washington, D.C., 1996)." Every effort has been made to minimize the suffering of the animals and to reduce the number of samples used.

\section{Preparation of $\boldsymbol{Q}$. cortex extract}

The preparation of $Q$. cortex extract included the following steps: Weighing $50 \mathrm{~g}$ amounts of shredded bark (medicinal form), placing the bark into heatproof ware with $500 \mathrm{ml}$ of hot $\left(70^{\circ} \mathrm{C}\right)$ distilled water, and heated in a water bath $(30 \mathrm{~min})$ followed by percolation and filtering (deashed filters "White Ribbon," d $70 \mathrm{~mm}$ APEXLAB).

\section{Broilers, management, and dietary treatments}

The research was performed at the center of collective use of scientific equipment of the Federal Research Centre of Biological Systems and Agro-technologies of the Russian Academy of Sciences on "Smena-8" broiler chickens. Acclimatization was conducted for 6 days from day 0 to day 6 , and each group was maintained in a $60 \mathrm{~cm} \times 50 \mathrm{~cm} \times 50 \mathrm{~cm}$ box equipped with an incandescent lamp to keep the temperature warm. Feeding began at the age of day 7 and continued to day 42 . For the experiment, 120 7-day-old broiler chickens were selected (4 groups, $n=30,3$ replicates with 10 birds in each group). The groups were as follows: The reference group - basic diet (BD) (Table-1); experimental Group I - BD +Q. cortex extract (Q. cortex), $2.5 \mathrm{ml} / \mathrm{kg}$ of body weight; experimental Group II - BD + probiotic preparation based on Bifidobacterium adolescentis - 80.0 million colony-forming units (CFU), and Lactobacillus acidophilus - 1.0 million CFU (dosage in accordance with the recommendations of the manufacturer); and experimental Group III - BD + probiotic + extract of $Q$. cortex.

Formulation of diets for the experimental poultry was based on the recommendations of VNITIP (The All-Russian Research and Technological Institute of Poultry). The microclimate in the room was consistent with the VNITIP recommendations and requirements [26]. The growth was monitored every day by individual weighing. Experimental poultry was fed twice a day; the consumption was recorded every day, $Q$. cortex extract was supplied in the drinking water. Poultry was decapitated under Nembutal ether on the $42^{\text {nd }}$ day.

\section{Sampling and analytical procedures}

Blood sampling was taken from the brown brachialis vein by as much as $1 \mathrm{cc}$. Blood samples for the study were placed in sterile vacuum tubes with anticoagulant EDTA and vacuum sterile tubes to produce blood serum.

The morphological indicators of blood were determined with the use of an automatic hematology analyzer URIT-2900 Vet Plus (Medial URIT Electronic Co., China). Biochemical analysis of blood serum was performed on the automatic biochemical analyzer 
Table-1: Ingredients and nutrient level of basal diets.

\begin{tabular}{lcc}
\hline Attributes & Starter (7-28 days) & Finisher (29-42 days) \\
\cline { 2 - 3 } & Controls I, II, and III & Controls I, II, and III \\
\hline Ingredient composition (\%) & & 43.0 \\
Wheat & 49.0 & 0.4 \\
Barley & 3.1 & 25.0 \\
Corn & 8.0 & 17.0 \\
Soybean meal (46\% CP) & 23.0 & 10.0 \\
Sunflower meal (38\% CP) & 5.0 & 5.0 \\
Sunflower oil & 5.0 & 1.4 \\
Di-calcium phosphate & 1.6 & 1.5 \\
Mel stern & 0.9 & 0.3 \\
Limestone & 0.5 & 0.22 \\
Salt & 0.32 & 0.16 \\
DL-methionine & 0.18 & 0.17 \\
L-Lysine & 0.35 & 2.0 \\
Vitamin-mineral premixaa & 2.0 & 302.0 \\
Calculated nutrients metabolizable energy (kkal/100 g) & 296.0 & 19.1 \\
Crude protein & 24.0 & 0.79 \\
Methionine+cysteine & 0.87 & 0.96 \\
Lysine & 1.35 & 1.0 \\
Calcium & 0.95 & 0.48 \\
Available phosphorus & 0.54 & \\
\hline
\end{tabular}

a Supplied following per kilogram of diet: Vitamin $A=7,000$ IU, Vitamin $D 3=800$ IU, Vitamin $E=9$ IU, Vitamin $K 3=1.1$ $\mathrm{mg}$, Thiamine: $0.7 \mathrm{mg}$, Riboflavin $=3.0 \mathrm{mg}$, Vitamin $B 6=1 \mathrm{mg}$, Vitamin $B 12=0.01 \mathrm{mg}$, Vitamin $C=50 \mathrm{mg}, \mathrm{Mn}=23 \mathrm{mg}$, $\mathrm{Fe}=17 \mathrm{mg}, \mathrm{Zn}=11 \mathrm{mg}, \mathrm{Cu}=2.5 \mathrm{mg}, \mathrm{I}=0.4 \mathrm{mg}, \mathrm{Se}=0.2 \mathrm{mg}$

CS-T240 ("Dirui Industrial Co., Ltd", China) with the use of commercially available biochemical veterinary kits DiaBet Test (Russia) and commercially available biochemical kits Randox Laboratories Limited, (UK). The following parameters were studied: Erythrocytes, platelets, leukocytes, lymphocytes, monocytes, granulocytes, hemoglobin, glucose, total protein, albumin, urea, bilirubin, cholesterol, triglycerides, creatinine, calcium, phosphorus, iron, alanine aminotransferase (ALT), aspartate aminotransferase (AST), gamma-glutamyl transpeptidase, lactate dehydrogenase (LDH), superoxide dismutase (SOD), lysozyme activity of blood serum (LASK), and $\beta$-lysines.

Serum was studied no later than $2 \mathrm{~h}$ after sampling. The total amount of antioxidants was determined by measuring chemiluminescence of blood serum samples in the presence of luminol and hydrogen peroxide. During the experiments, indicators of natural resistance were determined: Activity of lysozyme, according to Ermolieva and Buyanovsky [27], and activity of $\beta$-lysines by the accelerated method of Bukharin [27].

\section{Statistical analysis}

Statistical analysis was performed using SPSS Statistics Version 20 (IBM, USA) program, which was used to calculate the average value (M), standard deviation error (m). Further analysis used the Wilcoxon signed-rank test, and results were considered significant with a level of $95 \%(\mathrm{p} \leq 0.05)$.

\section{Results and Discussion}

The values of hematological parameters obtained during this research were within the normal ranges as reported by Anon [28], indicating that poultry was adequately fed and therefore not anemic or showed no signs of diseases or parasitic problems (Table- 2). The number of blood corpuscles in experimental Group III was lower than those in other groups, lower the level of hemoglobin by $12.8 \%(\mathrm{p} \leq 0.05)$ compared to the reference group. These results differ from those obtained earlier; there are data on the lack of influence of probiotic drugs on the blood elements in the literature $[29,30]$. At the same time, it must be taken into account that we used other strains of probiotic bacteria.

Analysis of the data showed a decreased level of glucose and a decreased concentration of triglycerides in the blood of poultry in the experimental groups (Table-2), which might be due to the beneficial effect of the substances in the composition of the medicinal plants. Some flavonoids have insulin-like action and thus can reduce the level of glucose in the blood [31].

A decreased level of glucose in the blood of broilers with the introduction of tannic acid into the diet was observed in earlier studies [32], as well as triglycerides on feeding an essential oil mix obtained from plants [33]. It is known that triglycerides are important energy products, especially those used by chickens for growth $[34,35]$. In addition, a recent study [36] found that bifidobacteria inhibit fat accumulation, improve insulin resistance, and reduce blood glucose levels in the blood of laboratory animals.

High creatinine content was found in experimental Group III, exceeding the value in the reference group by $20.2 \%$ and exceeding the value of experimental Group I by $19.4 \%$ and experimental Group II by $10.1 \%$. Creatinine is another important indicator of protein metabolism as it is a by-product of 
Table-2: Morphological and biochemical parameters of broiler chicken blood.

\begin{tabular}{|c|c|c|c|c|}
\hline \multirow[t]{2}{*}{ Index } & \multicolumn{4}{|c|}{ Group } \\
\hline & Control & $\mathbf{I}$ & II & III \\
\hline Red blood cells, $10^{12} / \mathrm{I}$ & $2.06 \pm 0.14$ & $1.97 \pm 0.07$ & $1.93 \pm 0.08$ & $1.83 \pm 0.07$ \\
\hline Thrombocytes $10^{9} / \mathrm{I}$ & $67.50 \pm 7.35$ & $68.00 \pm 2.38$ & $63.25 \pm 2.78$ & $65.60 \pm 1.57$ \\
\hline Hemoglobin, g/l & $131.25 \pm 9.54$ & $127.75 \pm 4.96$ & $124.25 \pm 6.55$ & $114.40 \pm 4.47^{a}$ \\
\hline Glucose, mmol/l & $10.68 \pm 0.27$ & $10.40 \pm 0.10$ & $10.62 \pm 0.34$ & $10.50 \pm 0.11$ \\
\hline Total protein, g/l & $32.25 \pm 1.62$ & $33.86 \pm 0.29$ & $33.04 \pm 1.16$ & $32.06 \pm 0.47$ \\
\hline Albumin, $\mathrm{g} / \mathrm{l}$ & $13.25 \pm 0.75$ & $14.25 \pm 0.25$ & $14.00 \pm 0.71$ & $13.40 \pm 0.40$ \\
\hline Urea, mmol/l & $0.88 \pm 0.03$ & $0.93 \pm 0.03$ & $0.90 \pm 0.07$ & $0.90 \pm 0.05$ \\
\hline Direct bilirubin, $\mu \mathrm{mol} / \mathrm{l}$ & $0.41 \pm 0.02$ & $0.45 \pm 0.03$ & $0.43 \pm 0.04$ & $0.42 \pm 0.04$ \\
\hline Cholesterol mmol/l & $3.95 \pm 0.12$ & $3.96 \pm 0.10$ & $3.95 \pm 0.11$ & $3.75 \pm 0.20$ \\
\hline Triglycerides, mmol/l & $0.07 \pm 0.01$ & $0.03 \pm 0.02^{\mathrm{a}}$ & $0.05 \pm 0.02$ & $0.03 \pm 0.01^{\mathrm{a}}$ \\
\hline Creatinine, $\mu \mathrm{mol} / /$ & $70.65 \pm 8.13$ & $71.13 \pm 4.48$ & $77.18 \pm 10.49$ & $84.94 \pm 12.14$ \\
\hline Calcium, mmol/l & $2.53 \pm 0.06$ & $2.68 \pm 0.04$ & $2.45 \pm 0.06$ & $2.54 \pm 0.08$ \\
\hline Phosphorus, mmol/l & $2.07 \pm 0.28$ & $1.75 \pm 0.17$ & $2.59 \pm 0.85$ & $2.02 \pm 0.75$ \\
\hline Iron, $\mu \mathrm{mol} / \mathrm{I}$ & $28.8 \pm 0.80$ & $32.83 \pm 5.07$ & $37.50 \pm 3.05$ & $51.32 \pm 6.50^{\mathrm{a}}$ \\
\hline
\end{tabular}

${ }^{a} \mathrm{p} \leq 0.05$ in comparison with the control group

Table-3: The content of the white blood cells in broilers of cross "Smena 8 " in the context of introducing $Q$. cortex extract.

\begin{tabular}{lcccc}
\hline Index & \multicolumn{3}{c}{ Group } \\
\cline { 2 - 5 } & Control & I & II & III \\
\hline Leukocytes, $10^{9} /$ I & $19.9 \pm 6.21$ & $23.00 \pm 4.51$ & $16.33 \pm 2.38$ & $17.00 \pm 1.49$ \\
Percentage of lymphocytes & $85.95 \pm 1.17$ & $81.05 \pm 1.10$ & $85.53 \pm 0.64$ & $88.68 \pm 0.69$ \\
Percentage of monocytes & $6.98 \pm 0.48$ & $8.23 \pm 0.23^{\mathrm{a}}$ & $6.80 \pm 0.42$ & $5.86 \pm 0.31$ \\
Percentage of granulocytes & $7.08 \pm 0.78$ & $10.73 \pm 0.89$ & $7.68 \pm 0.38$ & $5.46 \pm 0.39$ \\
\hline
\end{tabular}

${ }^{a} \mathrm{p} \leq 0.05$ in comparison with control group. Q. cortex: Quercus cortex

phosphocreatine decomposition in skeletal muscles. Its concentration is directly proportional to the muscle weight associated with age, physical activity, and like most components of blood chemistry, which depend on the diet [37].

The indicators of mineral metabolism were within the norm in all examined chickens. The content of $\mathrm{Ca}$ in the group, with the introduction of $Q$. cortex extract into the diet, was higher than that of the reference group by $5.9 \%$ - however, the content of $\mathrm{P}$ in this group, relative to the reference, was lower than the reference by $15.4 \%$. A remarkable increase in the level of $\mathrm{Fe}$ in the three experimental groups was observed $-13.9 \%, 30.2 \%$, and $78.1 \%$, respectively, compared to the reference group. Although there was the tendency for a decrease in the number of erythrocytes in these groups, the probability of increasing the level of iron due to their destruction was insignificant, as it was known that tannic acid mitigated hepatotoxicity caused by iron [38], while probiotic strains could bind iron [39]. The obtained data contradict the information obtained previously [40], where feeding of grape seed extracts marked a decrease in iron and other minerals in the blood plasma of broilers.

The values of leukocytes in experimental Group I were higher by $15.6 \%$ compared to the reference group and by $40.8 \%$ and $35.3 \%$ compared to the other two experimental groups, respectively (Table-3).

This fact is in line with the previous studies performed with the use of thyme extract, which did not reveal any significant increase in the leukocyte count but improved the immunological response of broilers organisms [41]. The combination of the extract and the probiotic strain promotes indicators alignment with the reference group, which confirms the opinion that searching for synergistic substances is required for creating efficient feed additives [42]. The increase in lymphocytes in this group is confirmed by earlier conclusions [43] that bifidobacteria promote the activation of these cells in animals. The monocyte count in experimental Group I was higher by $17.9 \%$ compared to the reference group.

The levels of AST, ALT, LDH, and catalase activity were within the norm; however, we note a tendency for these values to fluctuate in the experimental groups (Table-4).

Thus, the ALT activity was remarkably high in experimental Group II; the value of this indicator in this group was higher by $25 \%, 18.7 \%$, and $16.4 \%$, compared to the reference group, experimental Groups I and III, respectively. The AST activity was also remarkably higher in experimental Group II, exceeding this indicator in the reference group by $16.4 \%$. The LDG activity in all groups was approximately the same; however, there was a decrease in this indicator in experimental Group II by $20.7 \%$, compared to the reference group.

A higher level of catalase was noted in experimental Group I; it exceeded the levels of the reference group by $27.2 \%(\mathrm{p} \leq 0.05)$. An increased antioxidant 
Table-4: Activity of blood serum enzymes and indicators of non-specific immunity in broilers of cross "Smena 8 " in the context $Q$. cortex extract.

\begin{tabular}{|c|c|c|c|c|}
\hline \multirow[t]{2}{*}{ Index } & \multicolumn{4}{|c|}{ Group } \\
\hline & Control & $\mathbf{I}$ & II & III \\
\hline ALT, units/I & $3.8 \pm 0.76$ & $4.0 \pm 0.36$ & $4.75 \pm 0.62^{a}$ & $4.08 \pm 0.68$ \\
\hline AST, units/I & $228.8 \pm 21.84$ & $219.6 \pm 12.53$ & $262.3 \pm 32.35^{a}$ & $227.32 \pm 10.85$ \\
\hline g-GT, units/I & $16.5 \pm 1.04$ & $18.3 \pm 2.85$ & $18.50 \pm 0.50$ & $19.00 \pm 1.82$ \\
\hline LDG, units/I & $14.2 \pm 3.68$ & $14.0 \pm 5.57$ & $11.25 \pm 3.33$ & $14.80 \pm 2.78$ \\
\hline SOD, \% & $879.8 \pm 54.2$ & $911.8 \pm 38.0$ & $995.9 \pm 52.4$ & $906.5 \pm 22.9$ \\
\hline Catalase, $\mu \mathrm{m} \mathrm{H}_{2} \mathrm{O}_{2} \mathrm{l} / \mathrm{per} / \mathrm{min}$ & $1,494.4 \pm 63.0$ & $1,901.0 \pm 53.3^{a}$ & $1,685.3 \pm 55.4$ & $1,537.3 \pm 51.8$ \\
\hline BSLA, \% & $47.1 \pm 0.39$ & $45.3 \pm 0.91$ & $48.9 \pm 1.2$ & $45.1 \pm 0.55$ \\
\hline$\beta$-lysines, $\%$ & $72.9 \pm 0.40$ & $79.3 \pm 0.80$ & $84.6 \pm 0.52^{a}$ & $80.5 \pm 0,51$ \\
\hline
\end{tabular}

${ }^{a} \mathrm{p} \leq 0.05$ in comparison with control group. ALT=Alanine aminotransferase; $A S T=$ Aspartate aminotransferase; g-GT=Gamma-glutamyl transpeptidase; LDH=Lactate dehydrogenase; SOD=Superoxide dismutase; BSLA=Lysozyme activity of blood serum, Q. cortex: Quercus cortex

Table-5: Weekly broiler chicken weight gain, g/head.

\begin{tabular}{lcccc}
\hline Age, days & \multicolumn{3}{c}{ Group } \\
\cline { 2 - 5 } & Control & I $^{\text {a }}$ & II & III \\
\hline 8 & $115.20 \pm 6.2$ & $114.60 \pm 9.1$ & $115.60 \pm 7.4$ & $114.20 \pm 8.5$ \\
15 & $299.50 \pm 15.4$ & $317.20 \pm 22.5$ & $321.60 \pm 21.7$ & $300.40 \pm 22.9$ \\
22 & $652.50 \pm 28.9$ & $618.80 \pm 43.5$ & $684.80 \pm 44.0$ & $638.80 \pm 32.3$ \\
29 & $1164.00 \pm 61.5$ & $1134.40 \pm 47.2$ & $1217.20 \pm 80.9$ & $1138.80 \pm 54.7$ \\
36 & $1787.00 \pm 82.2$ & $1660.00 \pm 53.5$ & $1797.60 \pm 56.0$ & $1682.80 \pm 68.7$ \\
42 & $2284.50 \pm 86.4$ & $2149.60 \pm 87.5$ & $2300.50 \pm 60.6$ & $2196.80 \pm 94.2$ \\
\hline
\end{tabular}

${ }^{a} \mathrm{p} \leq 0.05$ in comparison with the control group

activity on feeding with plant extracts was also noted by other researchers [44]. The introduction of the probiotic preparation into the diet influences activation of $\beta$-lysine in blood serum; this indicator increases by $16.1 \%(\mathrm{p} \leq 0.05)$, compared to the reference group. This fact is consistent with the results of previous studies [45].

The use of $Q$. cortex extract and the probiotic preparation in the diet influenced the poultry growth rates (Table-5).

Thus, an increase in the live weight of 15-dayold chickens in experimental Groups I and II by 5.9\% and $7.4 \%(\mathrm{p} \leq 0.05)$ compared to the reference groups, respectively, was noted. This superiority was visible until the end of the accounting period, in which broilers in experimental Group II were superior to their peers in experimental Group I by $7 \%$ and in experimental Group III by $4.7 \%$. The cost of feed over the entire period of the experiment in the three experimental groups was lower than in the reference by $13.9 \%$, $5.8 \%$, and $6.8 \%$, respectively. A decreased feed consumption per $1 \mathrm{~kg}$ of live weight gain was noted in all experimental groups. Thus, this indicator in broiler chickens from experimental Groups I, II, and III was lower by $3.6 \%, 6.7 \%$, and $3.1 \%$, respectively, compared to the reference group. This result was consistent with earlier works that indicated an increase in feed consumption [46] and improvements in digestion [47] in cases of feeding poultry using diets prepared with the introduction of herbs and various plant extracts. Herbs and their extracts are known to increase the nutrient requirements of animals [48] due to the complex composition of their constituent biologically active substances, as well as due to the influence of several unknown factors that have a stimulating effect on digestive enzymes [49]. There is possible synergy between combinations of substances [50-52].

\section{Conclusion}

According to the present study, it can be concluded that the synergistic effect of the combined use of $Q$. cortex extract and the probiotic preparation (based on B. adolescentis and L. acidophilus) in the feeding of broiler chickens is manifested in terms of improvement of immune responses and antioxidant activity of organisms compared with broiler chickens with similar growth rates but without the supplementation of this combination.

\section{Authors' Contributions}

GKD and SGR equally designed the experiment. NMK, YVS, INM, LAM, and BHG contributed equally to the experimentation. GKD and SGR wrote and edited the article. All authors read and approved the final manuscript.

\section{Acknowledgments}

This research was performed with financial support from the Russian Science Foundation (project \#16-16-10048).

\section{Competing Interests}

The authors declare that they have no competing interests. 


\section{References}

1. Castanon, J.I.R. (2007) History of the use of antibiotic as growth promoters in European poultry feeds. Poult. Sci., 86(11): 2466-2471.

2. Blajman, J.E., Zbrun, M.V., Astesana, D.M., Berisvil, A.P., Romero Scharpen, A., Fusari, M.L., Soto, L.P., Signorini, M.L., Rosmini, M.R. and Frizzo, L.S. (2015) Probiotics in broilers' rearing: A strategy for intensive production models. Rev. Argent. Microbiol., 47(4): 360-367.

3. Rostami, F., Ghasemi, H.A. and Taherpour, K. (2015) Effect of Scrophularia striata and Ferulago angulata, as alternatives to virginiamycin, on growth performance, intestinal microbial population, immune response, and blood constituents of broiler chickens. Poult. Sci., 94(9): 2202-2209.

4. Tipu, M.A., Akhtar, M.S., Anjum, M.I. and Raja, M.L. (2006) New dimension of medicinal plants as animal feed. Pak. Vet. J., 26(3): 144-148.

5. Shokri, A.N., Ghasemi, H.A. and Taherpour, K. (2017) Evaluation of Aloe vera and synbiotic as antibiotic growth promoter substitutions on performance, gut morphology, immune responses and blood constitutes of broiler chickens. Anim. Sci. J., 88(2): 306-313.

6. Ocak, N., Erener, G., Burak, A., Sungu, M., Altop, A. and Ozmen, A. (2008) Performance of broilers fed diets supplemented with dry peppermint (Mentha piperita L) or thyme (Thymus vulgaris L) leaves as growth promoter source. Czech. J. Anim. Sci., 53(4): 169-175.

7. Ge, H.M., Shen, Y., Zhu, C.H., Tan, S.H., Ding, H., Song, Y.C. and Tan, R.X. (2008) Penicidones A-C, three cytotoxic alkaloidal metabolites of an endophytic Penicillium sp. Phytochemistry, 69(2): 571-576.

8. Lipińska, L., Klewicka, E. and Sójka, M. (2014) The structure, occurrence and biological activity of ellagitannins: A general review. Acta Sci. Pol. Technol. Aliment., 13(3): 289-299.

9. Fan, S.H., Ali, N.A. and Basri, D.F. (2014) Evaluation of analgesic activity of the methanol extract from the galls of Quercus infectoria (Olivier) in rats. Evid. Based Complement Altern. Med., 2014: 976764.

10. Fisinin, V.I., Ushakov, A.S., Duskaev, G.K., Kazachkova, N.M., Nurzhanov, B.S., Rakhmatullin, S.H.G. and Levakhin, G.I. (2018) Mixtures of biologically active substances of oak bark extracts change immunological and productive indicators of broilers. Agric. Biol., 53(2): 385-392.

11. Sati, S.C., Sati, N. and Sati, O.P. (2011) Chemical investigation and screening of antimicrobial activity of stem bark of Quercus leucotrichophora. Int. J. Pharm. Pharm. Sci., 3: 89-91.

12. Sarwar, R., Farooq, U., Khan, A., Naz, S., Khan, S., Khan, A., Rauf, A., Bahadar, H. and Uddin, R. (2015) Evaluation of antioxidant, free radical scavenging, and antimicrobial activity of Quercus incana Roxb. Front. Pharm., 6: 277.

13. Popović, B.M., Štajner, D., Ždero, R., Orlović, S. and Galić, Z. (2013) Antioxidant characterization of oak extracts combining spectrophotometric assays and chemometrics. Sci. World J., 2013: 134656.

14. Ahmed, S.T., Mun, H.S., Islam, M.M., Kim, S.S., Hwang, J.A., Kim, Y.J. and Yang, C.J. (2014) Effects of Citrus junos by-products fermented with multistrain probiotics on growth performance, immunity, caecal microbiology and meat oxidative stability in broilers. Br. Poult. Sci., 55(4): 540-547.

15. Jamshidparvar, A., Javandel, F., Seidavi, A., Blanco, F.P., Marín, A.L.M., Ramírez, C.A., Buendía, E.A. and NúñezSánchez, N. (2017) Effects of golpar (Heracleum persicum Desf) and probiotics in drinking water on performance, carcass characteristics, organ weights, blood plasma constituents, and immunity of broilers. Environ. Sci. Pollut. Res. Int., 24(30): 23571-23577.
16. Waititu, S.M., Yitbarek, A., Matini, E., Echeverry, H., Kiarie, E., Rodriguez-Lecompte, J.C. and Nyachoti, C.M. (2014) Effect of supplementing direct-fed microbials on broiler performance, nutrient digestibilities, and immune responses. Poult. Sci., 93(3): 625-635.

17. Salim, H.M., Kang, H.K., Akter, N., Kim, D.W., Kim, J.H., Kim, M.J., Na, J.C., Jong, H.B., Choi, H.C., Suh, O.S. and Kim, W.K. (2013) Supplementation of direct-fed microbials as an alternative to antibiotic on growth performance, immune response, cecal microbial population, and ileal morphology of broiler chickens. Poult. Sci., 92(8): 2084-2090.

18. Pourakbari, M., Seidavi, A., Asadpour, L. and Martínez, A. (2016) Probiotic level effects on growth performance, carcass traits, blood parameters, cecal microbiota, and immune response of broilers. An. Acad. Bras. Cienc., 88(2): 1011-1021.

19. Zhen, W., Shao, Y., Gong, X., Wu, Y., Geng, Y., Wang, Z. and Guo, Y. (2018) Effect of dietary Bacillus coagulans supplementation on growth performance and immune responses of broiler chickens challenged by Salmonella enteritidis. Poult. Sci., 97(8): 2654-2666.

20. Li, Z., Wang, W., Liu, D. and Guo, Y. (2018) Effects of Lactobacillus acidophilus on the growth performance and intestinal health of broilers challenged with Clostridium perfringens. J. Anim. Sci. Biotechnol., 27(9): 25.

21. Wu, Y., Shao, Y., Song, B., Zhen, W., Wang, Z., Guo, Y., Shahid, M.S. and Nie, W. (2018) Effects of Bacillus coagulans supplementation on the growth performance and gut health of broiler chickens with Clostridium perfringens-induced necrotic enteritis. J. Anim. Sci. Biotechnol., 25(9): 9.

22. Wang, S., Peng, Q., Jia, H.M., Zeng, X.F., Zhu, J.L., Hou, C.L., Liu, X.T., Yang, F.J. and Qiao, S.Y. (2017) Prevention of Escherichia coli infection in broiler chickens with Lactobacillus plantarum B1. Poult. Sci., 96(8): 2576-2586.

23. Smialek, M., Burchardt, S. and Koncicki, A. (2018) The influence of probiotic supplementation in broiler chickens on population and carcass contamination with Campylobacter spp. Field study. Res. Vet. Sci., 14(118): 312-316.

24. Wang, H., Ni, X., Qing, X., Zeng, D., Luo, M., Liu, L., Li, G., Pan, K. and Jing, B. (2017) Live probiotic Lactobacillus johnsonii BS15 promotes growth performance and lowers fat deposition by improving lipid metabolism, intestinal development, and gut microflora in broilers. Front. Microbiol., 8: 1073.

25. Fisinin, V.I., Egorov, I.A., Okolelova, T.M. and Imangulov, S.H.A. (2010) Feeding of agricultural poultry. VNITIP, Sergiev Posad. p375.

26. Sadovnikov, N.V., Pridybailo, N.D., Vereshchak, N.A. and Zaslonov, A.S. (2009) General and special methods for studying blood of industrial bird crosses. Ural State Agricultural Academy, AVIVAK, Ekaterinburg-St. Petersburg. p85.

27. Forte, C., Moscati, L., Acuti, G., Mugnai, C., Franciosini, M.P., Costarelli, S., Cobellis, G. and TrabalzaMarinucci, M. (2016) Effects of dietary Lactobacillus acidophilus and Bacillus subtilis on laying performance, egg quality, blood biochemistry and immune response of organic laying hens. J. Anim. Physiol. Anim. Nutr. (Berl.), 100(5): 977-987.

28. Anon, A. (1980) Guide to the Care and Use of Experimental Animals. Canadian Council of Animal Care, Ottawa, Ontario, Canada. p85-90.

29. Wang, H., Ni, X., Qing, X., Liu, L., Xin, J., Luo, M., Khalique, A., Dan, Y., Pan, K., Jing, B. and Zeng, D. (2018) Probiotic Lactobacillus johnsonii BS15 improves blood parameters related to immunity in broilers experimentally infected with subclinical necrotic enteritis. Front. Microbiol., 30(9): 49.

30. Abdel-Hafeez, H.M., Saleh, E.S.E., Tawfeek, S.S., Youssef, I.M.I. and Abdel-Daim, A.S.A. (2017) Effects of probiotic, prebiotic, and synbiotic with and without feed restriction on performance, hematological indices and 
carcass characteristics of broiler chickens. Asian Australas. J. Anim. Sci., 30(5): 672-682.

31. Alimohamadi, K., Taherpour, K., Ghasemi, H.A. and Fatahnia, F. (2014) Comparative effects of using black seed (Nigella sativa), cumin seed (Cuminum cyminum), probiotic or prebiotic on growth performance, blood haematology and serum biochemistry of broiler chicks. J. Anim. Physiol. Anim. Nutr. (Berl), 98(3): 538-546.

32. Brahmachari, G. (2011) Bio-Flavonoids with Promising Antidiabetic Potentials: A Critical Survey. Opportunity, Challenge and Scope of Natural Products in Medicinal Chemistry, Kerala, India. p187-212.

33. Starčević, K., Krstulović, L., Brozić, D., Maurić, M., Stojević, Z., Mikulec, Ž., Bajić, M. and Mašek, T. (2015) Production performance, meat composition and oxidative susceptibility in broiler chicken fed with different phenolic compounds. J. Sci. Food Agric., 95(6): 1172-1178.

34. Murali, P., George, S.K., Ally, K. and Dipu, M.T. (2015) Effect of L-carnitine supplementation on growth performance, nutrient utilization, and nitrogen balance of broilers fed with animal fat. Vet. World, 8(4): 482-486.

35. Kikuchi, K., Othman, M.B. and Sakamoto, K. (2018) Sterilized bifidobacteria suppressed fat accumulation and blood glucose level. Biochem. Biophys. Res. Commun., 501(4): 1041-1047.

36. Wang, J., Wang, X., Li, J., Chen, Y., Yang, W. and Zhang, L. (2015) Effects of dietary coconut oil as a medium-chain fatty acid source on performance, carcass composition and serum lipids in male broilers. Asian Australas. J. Anim. Sci., 28(2): 223-230.

37. Obikaonu, H.O, Okoli I.C., Opara, M.N., Okoro, V.M.O., Ogbuewu, I.P., Etuk, E.B. and Udedibie, A.B.I. (2012) Haematological and serum biochemical indices of starter broilers fed leaf meal of neem (Azadirachta indica). J. Agric. Technol., 8(1): 71-79.

38. Szabo, A., Mézes, M., Horn, P., Sütö, Z., Bázár, G.Y. and Romvári, R. (2005) Developmental dynamics of some blood biochemical parameters in the growing turkey (Meleagris gallopavo). Act. Vet. Hung., 53(4): 397-409.

39. Basu, T., Panja, S., Shendge, A.K., Das, A. and Mandal, N. (2018) A natural antioxidant, tannic acid mitigates iron-overload induced hepatotoxicity in Swiss albino mice through ROS regulation. Environ. Toxicol., 33(5): 603-618.

40. Skrypnik, K. and Suliburska, J. (2017) Association between the gut microbiota and mineral metabolism. J. Sci. Food Agric., 98(7): 2449-2460.

41. Chamorro, S., Viveros, A., Centeno, C., Romero, C., Arija, I. and Brenes, A. (2013) Effects of dietary grape seed extract on growth performance, amino acid digestibility and plasma lipids and mineral content in broiler chicks. Animal, 7(4): 555-561.

42. Hidalgo-Cantabrana, C., Nikolic, M., López, P., Suárez, A.,
Miljkovic, M., Kojic, M., Margolles, A., Golic, N. and Ruas-Madiedo, P. (2014) Exopolysaccharide-producing Bifidobacterium animalis Subsp. Lactis strains and their polymers elicit different responses on immune cells from blood and gut associated lymphoid tissue. Anaerobe, 26: 24-30.

43. Alipour, F., Hassanabadi, A., Golian, A. and NassiriMoghaddam, H. (2015) Effect of plant extracts derived from thyme on male broiler performance. Poult. Sci., 94(11): 2630-2634.

44. Caly, D.L., D'Inca, R., Auclair, E. and Drider, D. (2015) Alternatives to antibiotics to prevent necrotic enteritis in broiler chickens: A microbiologist's perspective. Front. Microbiol., 6: 1336.

45. Sahu, J., Koley, K.M. and Sahu, B.D. (2017) Attribution of antibacterial and antioxidant activity of Cassia tora extract toward its growth promoting effect in broiler birds. Vet. World, 10(2): 221-226.

46. Mashayekhi, H., Mazhari, M. and Esmaeilipour, O. (2018) Eucalyptus leaves powder, antibiotic and probiotic addition to broiler diets: Effect on growth performance, immune response, blood components and carcass traits. Animal, 12(10): 2049-2055.

47. Diaz-Sanchez, S., D’Souza, D., Biswas, D. and Hanning, I. (2015) Botanical alternatives to antibiotics for use in organic poultry production. Poult. Sci., 94(6): 1419-1430.

48. Frankic, T., Voljg, M., Salobir, J. and Rezar, V. (2009) Use of herbs and spices and their extracts in animal nutrition. Acta Argic. Slov., 94(2): 95-102.

49. Jang, I.S., Ko, Y.H., Kang, S.Y. and Lee, C.Y. (2007) Effect of commercial essential oil on growth performance, digestive enzyme activity and intestinal microflora population in broiler chickens. Anim. Feed Sci. Technol., 134(3-4): 304-315.

50. Shekar, B.R., Nagarajappa, R., Jain, R., Singh, R., Thakur, R. and Shekar, S. (2016) Antimicrobial efficacy of Acacia nilotica, Murraya koenigii (L.) sprengel, Eucalyptus hybrid, Psidium guajava extracts and their combination on Streptococcus mutans and Lactobacillus acidophilus. Dent. Res. J. (Isfahan), 13(2): 168-173.

51. Jaeyoung, H., Minseok, S., Hwanhee, P., Woon, K.L., Le, L.G., Joon, Y., Kelsey, C.A., Hyeonju, A., Se-Young, K., Yoon-Mo, K., Seoae, C. and Heebal, K. (2016) Gut microbiota modulated by probiotics and Garcinia cambogia extract correlate with weight gain and adipocyte sizes in high fat-fed mice. Sci. Rep., 6: 33566.

52. Ayrle, H., Mevissen, M., Kaske, M., Nathues, H., Gruetzner, N., Melzig, M. and Walkenhorst, M. (2016) Medicinal plants-prophylactic and therapeutic options for gastrointestinal and respiratory diseases in calves and piglets? A systematic review. BMC Vet. Res., 12(1): 89. 